\title{
Supranacionalidade e Direitos Fundamentais: Efetividade do Direito Derivado na Comunidade Andina e no Sistema Centro-Americano de Integração
}

\author{
Eduardo Biacchi Gomes \\ Graduação em Direito pela Pontifícia Universidade Católica do Paraná (1993). Doutorado (20030 e Mestrado (2000) em Direito pela \\ Universidade Federal do Paraná. Especialização em Direito Internacional pela Universidade Federal de Santa Catarina (2001). \\ Pós-Doutorado em Estudos Culturais junto a Universidade Federal do Rio de Janeiro, com estudos realizados na Universidade \\ de Barcelona. Desenvolveu pesquisa na Universidade de Los Andes, Chile. Realiza estágio de Pós-Doutoramento na PUCPR. \\ Professor-adjunto integrante do quadro da UniBrasil. Professor titular de Direito Internacional da Pontifícia Universidade Católica do \\ Paraná. Professor-adjunto do curso de Direito Uninter e professor-colaborador do Mestrado em Direito da mesma instituição. \\ Tem experiência na área de Direito, com ênfase em Direito Internacional e Direito da Integração e Direitos Humanos, atuando \\ principalmente nos seguintes temas: blocos econômicos, direito comunitário, direito internacional público, direito da \\ integração, Mercosul e direito constitucional. Vice-coordenador do Programa de Mestrado em Direito da UniBrasil. \\ http://lattes.cnpq.br/0011551326068336. https://orcid.org/0000-0002-7721-0802. eduardobiacchigomes@gmail.com
}

\section{Luis Alexandre Carta Winter}

Graduação em Direito pela Universidade Federal do Paraná (1984). Especialização em Filosofia da Educação pela Pontifícia Universidade Católica do Paraná (1988). Mestrado em Integração Latino-Americana pela Universidade Federal de Santa Maria (2001). Doutorado em Integração da América Latina pelo USP/Prolam (2008). Professor titular da Pontifícia Universidade Católica do Paraná e da Unicuritiba. Consultor jurídico, atuando principalmente nos seguintes temas e áreas: contratos; integração regional; Mercosul; relações internacionais; direito marítimo; direitos humanos; direito humanitário; legislação aduaneira; direito internacional econômico e direito internacional. Coordenador do Núcleo de Estudos Avançados de Direito Internacional e Desenvolvimento Sustentável - Neadi (www.neadi.com.br).

Membro do Centro de Letras do Paraná e do Instituto de Advogados do Paraná. http://lattes.cnpq.br/2297481657152874. https://orcid.org/0000-0002-0116-6155. luisalexandrecartawinter@yahoo.com.br

\section{RESUMO}

A efetivação dos direitos fundamentais dentro de um bloco econômico depende dos mecanismos jurídicos e institucionais adotados internamente e da efetiva observância, por parte dos Estados, no sentido de cumprirem com o ordenamento jurídico do bloco. Nos modelos de blocos econômicos regidos pela intergovernabilidade, tendo em vista a ausência de um ordenamento jurídico supranacional, alguns entendem ser duvidoso o alcance das políticas integracionistas. Já nos blocos econômicos supranacionais, em que existe um ordenamento jurídico superior aos ordenamentos jurídicos dos Estados, a efetividade das respectivas políticas é maior, como o caso da União Europeia.

Palavras-chave: Blocos econômicos. Controle de convencionalidade. Direitos fundamentais. Integração regional.

\section{SUPRANATIONALISM AND FUNDAMENTAL RIGHTS: THE EFFECTIVITY OF THE SECONDARY LEGISLATION IN THE ANDENEAN COMMUNITY SYSTEM AND COMMUNITY AND IN THE CENTRAL AMERICAN INTEGRATION}

\section{ABSTRACT}

The enforcement of fundamental rights in an economic bloc depends on the legal and institutional mechanisms that are adopted internally to make effective the compliance by the states in order to observe with the integration law. In models of economic blocks that adopted the intergovernmentalism system, in view of the absence of a supranational legal system, some understand to be doubtful reach of integrationist policies. Already, the supranational economic blocks, where there is a higher than the legal systems of States legal system, the effectiveness of their policies is greater, as the case of the European Union.

Keywords: Economic blocks. Conventionality control. Fundamental rights. Regional integration.

1 Introdução. 20 Adensamento do Ordenamento Jurídico Supranacional. 3 Reenvio prejudicial e o Ordenamento jurídico comunitário. 4 Comunidade Andina de Nações e Sistema Centro-Americano: Direito Supranacional Híbrido? 3.1 Controle de convencionalidade nos blocos econômicos supranacionais e a efetivação dos direitos fundamentais. 4 Considerações finais. 5 Referências. 


\section{INTRODUÇÃO}

Nos processos de integração supranacionais, como é o caso da União Europeia, o ordenamento jurídico comunitário pode ser considerado o modelo ideal para a concretização dos objetivos integracionistas, principalmente em relação às políticas voltadas para os indivíduos, que são os verdadeiros destinatários das políticas adotadas dentro do bloco econômico.

A título de exemplo, citem-se os europeístas, que são os teóricos (cientistas políticos, juristas, filósofos, etc.), que defendem a ideia de uma integração maior da União Europeia, a qual, consequentemente, somente pode ser efetivada mediante um adensamento do ordenamento jurídico supranacional. De outro lado, os eurocéticos, ao adotarem uma política mais pessimista em relação aos rumos da integração da União Europeia, defendem a preservação das soberanias dos Estados membros do bloco, como forma de que possuam a devida autonomia para adotarem as políticas voltadas a atender aos interesses de seus nacionais.

Independentemente do posicionamento adotado dentro dos modelos de integração supranacional, como a União Europeia e em menor grau a Comunidade Andina de Nações e o Sistema de Integração Centro-americano, para que haja a efetividade das políticas integracionistas, adotadas pelas instituições do bloco, torna-se necessário o cumprimento, por parte dos Estados que compõem os blocos econômicos, do respectivo ordenamento jurídico em prol dos interesses de seus nacionais.

Como forma de materializar a efetivação e o cumprimento das referidas normas, torna-se necessário uma efetiva atuação - por parte das instituições supranacionais - no sentido de velar pela correta interpretação e aplicação das referidas normativas, dentro dos ordenamentos jurídicos dos Estados. A título de exemplo, cite-se a atuação do Tribunal de Justiça da União Europeia, por meio do reenvio prejudicial.

O reenvio prejudicial, instrumento processual adotado pelos sistemas de solução de controvérsias dos blocos econômicos supranacionais, permitem o efetivo diálogo entre as jurisdições nacionais e a supranacional, de forma a garantir a uniformidade na interpretação e na aplicação das referidas normas dentro dos ordenamentos jurídicos dos Estados.

Dentro dos blocos econômicos de natureza jurídica intergovernamental, como o caso do Mercosul, torna-se necessário garantir a primazia do ordenamento jurídico do bloco perante o dos Estados-partes.

Trata-se, portanto, de se garantir a efetividade no cumprimento das normativas comunitárias, de forma a assegurar a primazia das normativas do bloco ante os ordenamentos jurídicos dos Estados.

O presente artigo tem por finalidade examinar a possibilidade de se aplicar o controle de convencionalidade dentro dos processos de integração supranacionais híbridos. Para tanto, torna-se necessário analisar a própria construção do direito comunitário, com a atuação do Tribunal de Justiça da União Europeia e a sua aplicação em outros sistemas que adotam tal ordenamento jurídico sem o mesmo sucesso, como no caso da Comunidade Andina de Nações (CAN) e do Sistema de Integração Centro-Americano (Sica). 


\section{Humanos e \\ Democracia}

\section{O ADENSAMENTO DO ORDENAMENTO JURÍDICO SUPRANACIONAL}

Dentre os modelos de integração supranacionais, o exemplo de maior êxito é - inquestionavelmente - o da União Europeia, o qual, pela sua originalidade, criou um sistema jurídico independente e autônomo, diante do direito interno e do direito internacional, que é o direito comunitário (ou o direito supranacional). Características principais do ordenamento jurídico comunitário são: a) primazia das normas comunitárias perante as normativas dos Estado; ${ }^{1}$ b) aplicabilidade direta; ${ }^{2}$ e c) uniformidade na interpretação e na aplicação do direito comunitário. $^{3}$

Vale destacar a importante atuação, por parte da jurisprudência do Tribunal de Justiça da União Europeia, no que diz respeito à própria construção dos princípios do direito comunitário. Ademais, a efetividade no cumprimento do ordenamento jurídico comunitário, dentro da União Europeia, somente tornou-se possível graças à existência de uma política institucional voltada para o fortalecimento de suas instituições.

Ao mencionar as instituições supranacionais da União Europeia, vale a pena citar, além do Tribunal de Justiça da União Europeia, que tem a sua sede em Luxemburgo e por competência velar pela efetiva interpretação e aplicação do direito supranacional, os seguintes órgãos:

a) Parlamento Europeu: composto pelos denominados Eurodeputados, eleitos diretamente pelos cidadãos da União Europeia e que representam os interesses nacionais dos Estados-membros do bloco;

b) Conselho: órgão comunitário dotado de competências executivas e que representa os interesses dos Estados-membros da União Europeia. Possui o poder decisório dentro do bloco. É composto pelos representantes dos Estados-membros do bloco;

c) Comissão: órgão de natureza jurídica supranacional, dotado de competências fiscalizatória e executiva, no que diz respeito à aplicação e execução das normativas comunitárias. É composto pelos comissários que atuam com total independência e autonomia ante os Estados que integram o bloco econômico.

Pode-se constatar, portanto, que a própria construção e evolução do direito comunitário, dentro da União Europeia, decorreram de uma conscientização, por parte dos Estados-membros daquele bloco econômico, que somente seria possível avançar dentro das políticas integracionistas e construir uma verdadeira Europa unida, capaz de superar os sofrimentos e

\footnotetext{
Pelo princípio da aplicabilidade direta, as normativas emanadas pelas Instituições do bloco, como no caso da União Europeia, e os regulamentos, os mesmos não necessitam ser internalizados dentro dos ordenamentos jurídicos dos Estados. Assim que publicados no Diário Oficial da União Europeia, passam a gerar efeitos aos seus destinatários: Estados, instituições bloco e particulares. Trata-se de um mecanismo de uniformização de temas de relevante interesse ao direito comunitário.

2 Pelo princípio da primazia na hipótese de conflito entre a normativa supranacional e as normativas internas, haverá a prevalência da normativa supranacional em relação àquelas matérias de competência legislativas das instituições do bloco.

3 Pelo princípio da uniformização na interpretação e na aplicação do direito comunitário, tais normativas devem ser interpretadas e aplicadas de maneira uniforme dentro das 28 jurisdições dos Estados membros do bloco, de forma a permitir a primazia do respectivo ordenamento jurídico ante os nacionais. Com o intuito de se garantir a aplicação do respectivo princípio, o mecanismo processual utilizado é o do reenvio prejudicial, que será abordado neste artigo e pelo qual o estudo do controle de convencionalidade é desenvolvido. FONTOURA, Jorge. Fontes e formas para uma disciplina jurídica comunitária. Informativo Mercosul. Comissão Parlamentar Conjunta do Mercosul. Seção Brasileira, v. 1, n. 3, p. 43, dez. 1996/jan. 1997.
} 
as mazelas ocorridas e vivenciadas durante a Segunda Guerra Mundial e evitar novos conflitos, por meio da formação de um bloco econômico de caráter supranacional, no qual as políticas pudessem ser observadas e executadas pelos Estados-membros. ${ }^{4}$

No plano da integração europeia, vale a pena destacar as ideias de Habermas, ${ }^{5}$ em que as instituições supranacionais buscam construir a legitimidade na adoção de suas políticas comuns, mediante o constante diálogo entre o ordenamento jurídico comunitário e os nacionais.

Dentro da União Europeia, Habermas ${ }^{6}$ parte do pressuposto de que os Estados que integram aquele bloco econômico são economias consolidadas em que existe o respeito aos valores multiculturais, direitos sociais e democráticos.

Aliás, a construção secular do conceito de Estado-Nação surgiu dentro do sucesso daquele projeto integracionista (a despeito da crise econômica mundial vivenciada desde o ano de 2008, a consequente redução dos direitos sociais e a intervenção direta das instituições supranacionais dentro de determinados Estados-membros da União Europeia, como o caso do Banco Central Europeu que, com suas políticas macroeconômicas, juntamente com o Fundo Monetário Internacional recomendam aos Estados menos desenvolvidos, como Grécia, Espanha, Portugal e Irlanda, a redução dos direitos sociais), e conclui-se que aquele bloco econômico é resultado da adoção de um projeto arquitetado desde o final da Segunda Guerra Mundial.

A realidade do ordenamento jurídico supranacional da União Europeia certamente não encontra precedentes em qualquer outro processo de integração, uma vez que a própria construção do Direito Comunitário é decorrente, como visto anteriormente, de uma atuação direta por parte do Tribunal de Justiça da União Europeia, com o intuito de justificar e explicar a necessidade de os Estados-membros do bloco cumprirem com as normativas supranacionais.

Aliás, a construção do instituto da supranacionalidade, que significa a existência de um ordenamento jurídico que está acima dos ordenamentos jurídicos dos Estados e que, portanto, legitima as instituições comunitárias na aplicação do direito comunitário, justifica o adensamento do direito comunitário na União Europeia e o constante diálogo entre as ordens jurídicas (supranacional e nacional). ${ }^{7}$

Também dentro da União Europeia, assim como dentro dos Estados-membros do bloco, existe uma clara consciência de que o Direito Comunitário deve ser observado e cumprido nos ordenamentos jurídicos dos Estados e, na hipótese de não observância, o Tribunal de Justiça da União Europeia poderá atuar por intermédio dos mecanismos processuais vigentes. ${ }^{8,9}$

\footnotetext{
${ }^{4}$ A construção jurisprudencial do direito comunitário europeu. In: PIMENTEL, Luiz Otávio (org.). Mercosul no cenário internacional. Direito e Sociedade. Curitiba: Juruá, 1998. p. 293.

HABERMAS, J. A constelação pós-nacional. Ensaios políticos. São Paulo: Littera Mundi, 2001. p. 69.

HABERMAS, J. A inclusão do outro. São Paulo: Loyola, 2002. p. 141.

TEIXEIRA, Antonio Fernando Dias. A natureza jurídica das Comunidades Européias. Coimbra: Almedina, 1993. p. 193 et seq.

Ação por Incumprimento, Recurso por Omissão, Recurso de Anulação e o Reenvio Prejudicial.

CAMPOS, João Mota de. Direito comunitário. 4. ed. Lisboa: Calouste Gulbenkian, 1994. p. 401 et seq. V. 2.
} 


\section{Humanos \\ Democracia}

Ainda que o Direito Comunitário tenha sido construído por meio de uma longa construção jurisprudencial, houve uma assimilação, por parte dos ordenamentos jurídicos dos Estados-membros do bloco, em relação à sua aplicação e observância. Além disso, nunca é demais lembrar que as próprias instituições do bloco, que possuem a natureza jurídica verdadeiramente supranacional, adotam as políticas voltadas a atender aos interesses do próprio bloco econômico, mesmo que, muitas vezes, tais decisões possam contrariar os interesses dos Estados, de forma a garantir, assim, a independência e a autonomia na tomada das suas decisões pró-Europa.

Para que as políticas supranacionais, portanto, possam ser adotadas, torna-se necessário o constante diálogo entre o ordenamento jurídico supranacional e os ordenamentos jurídicos dos Estados-membros do bloco que, por sua vez, devem aceitar - em seus ordenamentos jurídicos - a adoção de tais políticas e legislações.

Trata-se da adoção das chamadas cláusulas de abertura, existentes dentro dos ordenamentos constitucionais dos Estados-membros do bloco, de forma a permitir a transferência ou a delegação de competências soberanas para as instituições do bloco econômico. Vide, como exemplo, a Constituição da Alemanha, ${ }^{10,11}$ que admite, em seu ordenamento jurídico, a transferência de soberania às instituições supranacionais, de forma a observar os direitos humanos e a democracia. ${ }^{12}$

No caso dos ordenamentos jurídicos nacionais e o supranacional, no que diz respeito à supranacionalidade e à transferência de soberania, sempre deverão estar presentes as políticas voltadas para a proteção dos direitos humanos e da democracia que, aliás, são pilares essenciais dentro do Tratado da União Europeia, como a inclusão da Carta Europeia de Direitos Fundamentais dentro do acervo jurídico supranacional, de forma - inclusive - a reforçar o exercício das quatro liberdades existentes dentro do bloco: livre-circulação de bens, pessoas, serviços e de capitais da própria Europa e, posteriormente, devido ao processo de colonização da América, Revoluções francesa e norte-americana, tais valores influenciaram diretamente na construção das democracias sul-americanas. ${ }^{13}$

O Tratado Reformador de Lisboa, ademais, aperfeiçoou os mecanismos institucionais vigentes dentro da União Europeia, de forma a dar mais transparência às políticas adotadas dentro do bloco econômico, de modo a tornar o bloco econômico um espaço supranacional

\footnotetext{
${ }^{10}$ Artículo 23.1. Para la realización de una Europa unida, la República Federal de Alemania contribuirá al desarrollo de la Unión Europea, dentro de su compromiso con los princípios democráticos, del Estado de Derecho, sociales y federativos y con el principio de la subsidiariedad y de garantizar una protección de los derechos fundamentales comparable en lo esencial a de la presente Ley Fundamental. Para ello, la Federación podrá transferir derechos de soberanía con el consentimiento del Consejo Federal. [...].

${ }^{11}$ LLORENTE, F. R.; PÉREZ, M. D. Constituciones de la Unión Europea. Barcelona: Ariel, 1997. p. 8.

${ }^{12}$ No mesmo sentido, a Constituição da Holanda, no artigo 28, §§ 2ㅇ e 3‥ 0 § 2ㅇ do artigo 28 prevê a delegação de competências soberanas. $\mathrm{O} \S 3$ o torna possível a limitação de sua soberania em relação a questões que sejam relevantes e de interesse nacional, desde que respeitados os direitos fundamentais do homem, o regime democrático de direito e os princípios da legalidade e reciprocidade. Ambos os institutos não se confundem, pois a delegação de competências soberanas não implica limitação de soberania. A limitação de soberania a que alude o texto constitucional grego se refere a casos específicos - desde que presente o interesse nacional - não contemplados pelo conceito de delegação de competências soberanas ora analisado. Trata-se de conceitos distintos, pois a norma regulamenta separadamente ambas as hipóteses.

${ }^{13}$ BALDI, César Augusto. Novo constitucionalismo latino-americano: considerações conceituais e epistemológicas. In: WOLKMER, Antonio Carlos; CORREAS, Oscar (org.). Crítica jurídica na América Latina. Aguas Calientes; Florianópolis: Centro de Estudios Jurídicos y Sociales Mispat; Universidade Federal de Santa Catarina: 2013. p. 91-92.
} 
mais democrático e com a adoção de políticas voltadas para a proteção dos Direitos Fundamentais, o que somente poderá ser concretizado desde que exista uma clara atuação das instituições supranacionais neste sentido, e uma própria consciência dos Estados-membros do bloco na direção de atuarem na defesa dos interesses dos cidadãos da União Europeia que, em última instância, são os verdadeiros destinatários das respectivas políticas comuns adotadas dentro daquele bloco econômico. ${ }^{14}$

Com o intuito de se concretizar as políticas da União Europeia, como supramencionado, torna-se necessário que os juízes nacionais apliquem e observem - de maneira uniforme - o direito supranacional. A concretização do princípio da uniformidade na interpretação e aplicação do direito comunitário, se dá mediante o Reenvio Prejudicial, que permite uma cooperação entre as jurisdições nacionais e a supranacional.

\section{REENVIO PREJUDICIAL E O ORDENAMENTO JURÍDICO COMUNITÁRIO}

Como visto anteriormente, o Direito Comunitário é um direito sui generis e peculiar, uma vez que foi resultado de longa construção jurisprudencial com o intuito de melhor explicar e fundamentar a vinculação dos Estados em relação ao respeito às normas supranacionais. Para que as normativas e as políticas comunitárias sejam - de fato - observadas e aplicadas dentro dos ordenamentos jurídicos dos Estados-membros, torna-se necessário que os juízes nacionais interpretem e apliquem as normas supranacionais de maneira uniforme.

Verifica-se inicialmente, portanto, que, antes da existência de um mecanismo e de um ordenamento jurídico efetivo, como é o caso do Direito Comunitário, torna-se necessário que exista um comprometimento político dos Estados que integram o bloco, no sentido de observarem o cumprimento das normas, assim como a existência de instituições verdadeiramente supranacionais e que possam atuar, com total independência e autonomia, na hipótese do descumprimento das respectivas normas.

Trata-se da realidade vivenciada dentro da União Europeia que, ao longo dos seus mais de 50 anos de história, logrou êxito na construção de instituições supranacionais e verdadeiramente independentes dos respectivos Estados-membros. Cumpre destacar, ademais, que o próprio Direito Comunitário e a supranacionalidade surgem dentro da União Europeia decorrendo de uma necessidade dos organismos daquele bloco econômico em justificar a obrigatoriedade no cumprimento daquele direito.

Processualmente, uma das ações típicas de Direito Comunitário e que permitem o diálogo entre as jurisdições nacionais e a supranacional, de forma a garantir a uniformidade na interpretação e aplicação do direito supranacional, é o reenvio prejudicial. Trata-se de um processo de natureza consultiva, com decisão de natureza vinculativa e obrigatória, em que o

\footnotetext{
${ }^{14}$ Vale destacar que a realidade enfrentada pelos blocos econômicos existentes no hemisfério sul é completamente diversa daquela encontrada na União Europeia. Tal constatação se dá por inúmeros motivos, como as diferenças de questões históricas e econômicas existentes entre os países e pelo fato de que os blocos foram criados, inicialmente, como uma estratégia para buscar-se uma melhor inserção no mundo globalizado.
} 


\section{Humanos e \\ Democracia}

Tribunal de Justiça da União Europeia (TJUE), mediante provocação das instâncias nacionais, é compelido a interpretar determinada disposição do Direito Comunitário, obrigando os tribunais a observá-la em sua sentença. ${ }^{15}$

Trata-se de um peculiar e engenhoso mecanismo processual criado dentro do Direito Comunitário e copiado (sem o mesmo sucesso) dentro de outros blocos econômicos que tentam adotar a supranacionalidade (como a Comunidade Andina de Nações e o Sistema Centro-americano de Integração), e que permite às instâncias jurisdicionais nacionais aplicar, de forma homogênea, o Direito Comunitário, possibilitando a sua inter-relação com o TJUE.

No presente caso, o Tribunal de Justiça das Comunidades Europeias atuaria como uma espécie de corte constitucional, de forma a garantir e controlar a legalidade na aplicação e interpretação das normas comunitárias. ${ }^{16}$ No que diz respeito à legitimidade ativa, somente as partes integrantes em uma ação judicial que tramite na jurisdição nacional é que poderão suscitar o reenvio. Excepcionalmente poderão intervir os Estados-membros, Parlamento Europeu, Comissão e o Conselho.

Vale destacar que o processamento do reenvio, por parte do juiz nacional, para o Tribunal de Justiça da União Europeia, é facultativo nas instâncias em que cabem recursos e nas em que não cabe mais recurso, o processamento do reenvio é obrigatório. Ainda que a decisão proferida pelo Tribunal de Justiça da União Europeia, em relação à interpretação de uma normativa do bloco seja vinculante, caberá ao juiz nacional julgar a questão.

Na hipótese de aplicação equivocada por parte do juiz nacional, em relação ao Acórdão do Tribunal de Justiça da União Europeia, o Estado poderá ser responsabilizado, mediante a Ação por Incumprimento, ${ }^{17}$ oportunidade na qual o particular, concretamente, poderá solicitar o pronunciamento do TJUE para que seja constatado o descumprimento do Estado em relação a não observância de uma norma de Direito Comunitário, cabendo o pagamento de uma indenização em favor do particular.

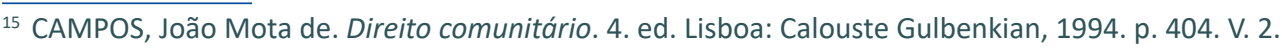

${ }^{16}$ No sistema do Reenvio Prejudicial, o TJUE é competente para se pronunciar sobre as questões advindas de interpretação do tratado; sobre a validade e interpretação dos atos praticados pelas instituições comunitárias e pelo Banco Central Europeu, e sobre a interpretação dos estatutos dos organismos criados pelo Conselho.

${ }^{17}$ Artigos 258 a 260 do Tratado sobre o Funcionamento da União Europeia.
} 
Aqui, vale a pena destacar o Acórdão Köbler, Processo C-224-01,18 movido por Gerhard Köbler diante da República da Áustria, em que se questionava a igualdade de tratamento em relação às remunerações pagas aos professores universitários e a consequente violação às normas de Direito Comunitário, de forma a reconhecer a responsabilidade do Estado em decorrência da inobservância do Direito da União Europeia. ${ }^{19}$

Dentro da União Europeia criou-se, portanto, um mecanismo todo peculiar que garante a própria eficácia no cumprimento do chamado Direito Comunitário derivado, diferente do chamado controle de convencionalidade, pelo qual o cumprimento das normativas internacionais depende de um efetivo controle por parte do Judiciário dos Estados.

Constata-se, então, que em relação ao Direito da União Europeia (Direito Comunitário), tendo em vista as características peculiares daquele ordenamento jurídico, de seus mecanismos processuais e da própria atuação do Tribunal de Justiça da União Europeia, a observância das normas supranacionais e a própria aplicação das sanções, é mais efetiva do que nos blocos econômicos que adotam o modelo intergovernamental. ${ }^{20}$

\footnotetext{
${ }^{18}$ Disponível em: http://curia.europa.eu/juris/liste.jsf?pro=\&nat=\&oqp=\&dates=\&lg=\&language=pt\&jur=C\%2CT\%2CF\&ci$\mathrm{t}=$ none $\% 252 \mathrm{CC} \% 252 \mathrm{CCJ} \% 252 \mathrm{CR} \% 252 \mathrm{C} 2008 \mathrm{E} \% 252 \mathrm{C} \% 252 \mathrm{C} \% 252 \mathrm{C} \% 252 \mathrm{C} \% 252 \mathrm{C} \% 252 \mathrm{C} \% 252 \mathrm{C} \% 252 \mathrm{C} \% 252 \mathrm{C} \% 252 \mathrm{Ctrue} \%$ 252Cfalse\%252Cfalse\&num=c\%2B-\%2B224\%252F01\&td=ALL\&pcs=O\&avg=\&page=1\&mat=or\&jge=\&for=\&cid=387738. Acesso em: 5 mar. 2014.

${ }^{19} \mathrm{O}$ princípio segundo o qual os Estados-membros são obrigados a ressarcir os danos causados aos particulares pelas violações do direito comunitário que lhes são imputáveis é igualmente aplicável quando a violação em causa resulte de uma decisão de um órgão jurisdicional decidindo em última instância, desde que a norma de direito comunitário violado se destine a conferir direitos aos particulares, que a violação seja suficientemente caracterizada e que exista um nexo de causalidade directo entre a violação e o dano sofrido pelas pessoas lesadas. A fim de determinar se tal violação é suficientemente caracterizada quando resulte dessa decisão, o juiz nacional competente deve, tendo em conta a especificidade da função judicial, apurar se essa violação tem carácter manifesto. É à ordem jurídica de cada Estado-membro que cabe designar o órgão jurisdicional competente para decidir os litígios relativos a tal ressarcimento. 2. Os artigos 48 do Tratado CE (que passou, após alteração, a artigo $39 \mathrm{CE}$ ) e $7^{\circ}$, n. 1, do Regulamento (CEE) n. 1.612/68 do Conselho, de 15 de Outubro de 1968, relativo à livre-circulação dos trabalhadores na Comunidade, devem ser interpretados no sentido de que se opõem à concessão, nas condições previstas no § 50a da Gehaltsgesetz 1956, na redacção de 1997, de um subsídio especial de antiguidade que, segundo a interpretação do Verwaltungsgerichtshof (Áustria) no seu acórdão de 24 de junho de 1998, constitui um prémio de fidelidade. 3. Uma violação do direito comunitário como a resultante, nas circunstâncias do caso no processo principal, do acórdão do Verwaltungsgerichtshof de 24 de junho de 1998 não tem o carácter manifesto exigido para que haja, por força do direito comunitário, responsabilidade de um Estado-membro por uma decisão de um dos seus órgãos jurisdicionais decidindo em última instância. Disponível em: http://curia.europa.eu/juris/liste.jsf?pro=\&nat=\&o$\mathrm{qp}=\&$ dates=\&lg=\&language=pt\&jur=C,T,F\&cit=none\%2CCCJ\%2CR\%2C2008E\%2C\%2C\%2C\%2C\%2C\%2C\%2C\%2C\%2C\%2Ctrue\%2Cfalse\%2Cfalse\&num=c+-+224\%2F01\&td=ALL\&pcs=0\&avg=\&page=1\&mat=or\&jge=\&for=\&cid=387738. Acesso em: 5 mar. 2014

${ }^{20}$ Neste sentido, vide que nos blocos econômicos intergovernamentais, como é o caso do Mercosul, regido pelo Direito Internacional Público, o cumprimento das normas emanadas pelo bloco se fundamentam no princípio pacta sunt servanda, artigos 27 e 46 da Convenção de Viena sobre Direito dos Tratados de 1969, sendo obrigação dos Estados e das jurisdições nacionais julgarem as controvérsias de acordo com as normativas do Mercosul, sob pena de ensejar a responsabilidade internacional do Estado. Aqui pode-se cogitar a aplicação do controle de convencionalidade dentro dos processos de integração intergovernamentais, até porque as suas normativas possuem a natureza jurídica de Direito Internacional, posto que nos blocos econômicos de natureza jurídica supranacional as normativas possuem esta característica.
} 


\section{Humanos e \\ Democracia}

\section{COMUNIDADE ANDINA DE NAÇÕES E SISTEMA CENTRO-AMERICANO: DIREITO SUPRANACIONAL HÍBRIDO?}

Se dentro da União Europeia o respectivo direito é aplicado de maneira efetiva, o mesmo não acontece na Comunidade Andina de Nações e no Sistema Interamericano de Integração, que são processos de integração que, pura e simplesmente, copiaram para os respectivos ordenamentos jurídicos dos blocos o modelo adotado no Velho Continente, sem levar em consideração as diferenças econômicas, sociais, culturais e políticas de seus membros.

O que se tem são sistemas híbridos de integração, isto é, que juridicamente adotam o Direito Comunitário, mas que na prática não é efetivo, quer pela ausência de vontade política de seus parceiros, quer pela falta de efetivas instituições supranacionais.

A Comunidade Andina (CAN), bloco de integração regional de natureza jurídica supranacional, foi criada com o intuito de consolidar-se em um mercado comum. É composta pela Bolívia, Colômbia, Equador e Peru, tendo sido fundada no ano de 1969 por meio do Acordo de Cartagena. No ano de 1979 foram instituídos o Tribunal e o Parlamento Andino, com a assinatura do Tratado do Tribunal de Justiça, em Cartagena, em 28 de maio, e do Tratado Constitutivo do Parlamento, em La Paz, em 25 de outubro.

O Protocolo de Trujillo, 1996, e o Protocolo de Sucre, 1997, alterou a estrutura do processo de integração e a denominação de Pacto Andino para a sua denominação e estrutura atual: Comunidade Andina de Nações.

Dentro da Comunidade Andina de Nações, ainda que os Estados-membros aceitem a aplicação e a observância do Direito Comunitário, pode-se constatar que a sua aplicação não se dá de forma efetiva, tendo em vista a ausência de instituições supranacionais que possam verdadeiramente fiscalizar o cumprimento das normativas supranacionais, assim como a ausência de uma verdadeira vontade política dos respectivos Estados, no sentido de verticalizarem a integração para a formação do mercado comum (ver em Arroyave-Quintero). ${ }^{21}$

Já o antigo Mercado Comum Centro-Americano foi criado pelo Tratado Geral de Integração Econômica Centro-Americana, Tratado de Manágua (1960), e reformulado pelo Protocolo de Tegucigalpa, em 13.12.1991, que criou o Sistema de Integração Centro-Americano (Sica). É composto de sete Estados: Belize, Costa Rica, El Salvador, Guatemala, Honduras, Nicarágua e Panamá. Esse Protocolo, fonte originária do bloco econômico, situa-se em grau de hierarquia superior ao dos demais tratados.

No que diz respeito à efetividade das normativas supranacionais, dentro do Sica, as críticas apresentadas em relação à Comunidade Andina também são aplicadas no presente caso.

\footnotetext{
${ }^{21}$ ARROYAVE-QUINTERO, M. A. Ineficacia crónica del derecho andino: uno de los factores importantes para el ocaso de la Comunidad Andina de Naciones (CAN). Papel Político, [on-line], 13, enero/jun. 2008. Disponível em: http://www.redalyc.org/ articulo.oa?id=77716563009. Acesso em: 4 marzo 2014.
} 
Conforme esclarecem Cézar Ernesto Salazar Grande e Enrique Napoleón Ulate Chacón, ${ }^{22}$ a observância do direito supranacional depende da vontade política dos representantes dos Estados que integram o bloco ante a ausência de instituições fortes, capazes de fiscalizar o cumprimento das normativas, que se traduz na insegurança jurídica comunitária.

Diferentemente do modelo supranacional da União Europeia, portanto, o Direito Comunitário, adotado tanto pela Comunidade Andina de Nações quanto pelo Sistema Centro-Americano de Integração, depende da atuação dos funcionários e agentes nacionais e das próprias Cortes Nacionais, no sentido de velar pelo correto cumprimento das normativas supranacionais, podendo-se falar, aqui, do Controle de Convencionalidade, por se tratarem de sistemas híbridos de integração, pois, muito embora adotem o Direito Comunitário, a sua aplicação e observância não é efetiva.

\subsection{Controle de convencionalidade nos blocos econômicos supranacionais e a efetivação dos direitos fundamentais}

A realidade dos processos de integração da Comunidade Andina de Nações e do Sistema Centro-Americano de Integração, ainda que adotem o Direito Comunitário como pressuposto para concretizar os objetivos do mercado comum, é totalmente diferente daquela encontrada dentro da União Europeia, como visto anteriormente.

Muito embora as jurisprudências, tanto da Corte Centro-Americana de Justiça quanto do Tribunal de Justiça Andino, reconheçam a existência do Direito Comunitário dentro dos respectivos processos de integração e todos os seus efeitos jurídicos, daí decorrentes da aplicação de suas normas, como o primado da norma comunitária ante o ordenamento jurídico nacional dos Estados, a uniformidade na interpretação e na aplicação do Direito Comunitário e a aplicabilidade direta das respectivas normas, o grande problema reside na ausência de efetividade no cumprimento e na observância do Direito Comunitário dentro dos ordenamentos jurídicos dos Estados, e pela ausência de verdadeiras instituições supranacionais.

Aliás, diga-se de passagem, a realidade europeia, com a existência de instituições supranacionais, é totalmente diferente daquela encontrada tanto no Sistema Centro-Americano de Integração quanto na Comunidade Andina de Nações, tendo em vista que nestes modelos de integração, por fatores políticos, financeiros e por razões de Estado, não existe um campo fértil para a construção de verdadeiras instituições supranacionais, dotadas de competências para adotarem políticas de acordo com os interesses do bloco econômico.

Cumpre destacar que os Estados latino-americanos e os dos centro-americanos, colonizados pelos países ibero-americanos, ainda guardam resquícios da soberania em seu grau absoluto, o que desfavorece a qualquer política integracionista em maior grau.

Assim, manifesta-se a doutrina sobre a referida dualidade, que são os blocos econômicos supranacionais e a questão da soberania dos Estados.

Conforme Luis Alexandre Carta Winter e Marcos Waschowski, ${ }^{23}$

\footnotetext{
${ }^{22}$ GRANDE, C. E. S.; CHACÓN, E. N. U. Manual de Derecho Comunitário Centroamericano. 2. ed. El Salvador: El Dorado de Talleres Impresiones, 2013. p. 245.

${ }^{23}$ WINTER, L. A. C.; WASCHOWSKI, M. Estado: construção de uma identidade. CONPEDI DE MANAUS. Anais [...]. Disponível em: http://www.conpedi.org.br/manaus/arquivos/anais/bh/luis_alexandre_carta_winter.pdf. Acesso em: 5 mar. 2014.
} 


\section{Democracia}

Humanos e

A criação de um ordenamento jurídico dentro de um bloco econômico desenvolvido por órgãos funcionando com caráter permanente, tomando decisões vinculantes não só para os Estados, como também para cidadãos e empresas, leva a que os sistemas jurídicos se sobreponham num mesmo espaço territorial e a que os indivíduos se sintam duplamente vinculados. O Estado deixa de ser dono de algumas das suas políticas, que, historicamente, eram suas, perde a jurisdição sobre certas matérias, é obrigado a harmonizar a sua legislação com a dos restantes Estados, parte do fenômeno de integração, e, isto é o mais importante, muitas vezes, sem o seu consentimento (caso das decisões tomadas por maioria quando se defronta com a supranacionalidade).

Veja-se que o próprio conceito de soberania é resultante da necessidade que surgiu a partir da criação do Estado moderno (Paz de Vestfália, 1648) como forma de justificar e fundamentar o império do agora soberano sobre os seus jurisdicionados. A partir da Revolução Francesa (1789) surge o conceito de Estado-nação, com o consequente deslocamento da titularidade do poder soberano, que, antes, era do monarca e, agora, passa ao povo. Justamente com o intuito de o monarca preservar a sua unidade territorial e jurisdicional, são criados alguns elementos que passam a identificar o povo ao Estado, como a nacionalidade, a cidadania, a bandeira, o hino, o idioma, etc., conforme citado na obra "Democracia e Direitos Fundamentais na União Européia: a questão do multiculturalismo" de Eduardo Biacchi Gomes (2011).

Dentro da mesma lógica do raciocínio, os Estados do Continente Americano foram colonizados a partir da matriz europeia, e, assim, todos aqueles valores alusivos ao conceito de Estado moderno, Estado-nação e, principalmente, os relativos à soberania, foram introduzidos do Velho Continente, para o Novo Mundo.

Diferentemente, todavia, da Europa, que atravessou duas grandes guerras e, por necessidade de se reconstruir e de repensar o conceito de soberania na América, os valores soberanos permaneceram os mesmos, o que faz com que os Estados não adotem políticas comuns em prol de interesses supranacionais pelo simples motivo de que o poder soberano ainda permanece como um elemento central para as respectivas nações.

Assim, retomando-se a ideia central do presente artigo, ainda que nos sistemas regionais de integração, ora analisados, admita-se a existência do Direito Comunitário, ${ }^{24}$ como no caso das jurisprudências da Corte Centro-Americana, cujos pronunciamentos, diga-se de passagem, são louváveis, torna-se difícil colocar as respectivas decisões, tendo em vista o resquício do conceito absoluto de soberania existente entre os respectivos Estados.

\footnotetext{
${ }^{24}$ Expediente 23.9.2009 publicado pela Corte Centro-Americana de Justiça em 28.10.2009, em pronunciamento a título prejudicial em que reconheceu-se que é de competência da Corte garantir o respeito à interpretação e aplicação do Direito Comunitário na América Central, assim como a obrigatoriedade do Direito Comunitário em relação aos ordenamentos jurídicos dos Estados-partes do Sica, cujas normas prevalecem sobre os ordenamentos jurídicos nacionais, garantindo-se a aplicação do princípio do primado. Na hipótese de descumprimento das normativas, os tribunais nacionais podem aplicar as respectivas sanções ao Estado. Disponível em: http://portal.ccj.org.ni/CCJ2/Default.aspx?tabid=114. Acesso em: 5 mar. 2014.
} 
Dentro do Sistema Centro-Americano de integração existem as condições jurídicas para a adoção do Direito Comunitário, uma vez que existem cláusulas de abertura nas respectivas constituições dos Estados-partes, de forma - a exemplo das Constituições dos Estados-membros da União Europeia - a admitir a respectiva transferência de soberania às instituições supranacionais. ${ }^{25}$

\footnotetext{
${ }^{25}$ Neste sentido vide Cesar Ernesto Salazar Grande e Enrique Napoleón Ulalte Chacón (Manual de Derecho Comunitário Centroamericano. 2. ed. El Salvador: El Dorado de Talleres Impresiones, 2013. p. 116 et seq.), que, ao examinar os dispositivos das Constituições dos Estados-partes do Sica, esclarecem que: "La Constitución Política de Costa Rica presenta importantes reformas constitucionales en 1968, cuando se reforman los artículos 7 y 121 (reformados por Ley n. 4.123, del 31 de mayo de 1968). En el primero, se reconoce que los Tratados internacionales tienen autoridad superior a las leyes, y la Jurisprudencia admite en materia de derechos humanos su primacía sobre la misma Constitución (Sala Constitucional, Voto 3435-92). En el segundo (art. 121, inciso 4) autoriza la posibilidad de atribuir o transferir competencias a un ordenamiento jurídico comunitario, con el propósito de realizar objetivos regionales y comunes, para cuya aprobación se requiere una mayoría calificada, es decir, dos tercios de los votos del Parlamento; sin embargo, los Protocolos de menor rango derivados de tratados públicos no requieren aprobación legislativa, cuando los tratados autoricen de modo expreso tal derivación." (....) "La Constitución salvadoreña del 15 de diciembre de 1983 y sus reformas alienta y promueve una integración global, establece la posibilidad de crear mediante tratados 'organismos con funciones supranacionales' (artículo 89) abriendo así las puertas a la reconstrucción de la República de Centro América 'en forma unitaria, federal o confederada', bajo el respeto de los principios democráticos y los derechos fundamentales, sujetando el proyecto y bases de la unión a consulta popular. En las Actas de la Asamblea Nacional Constituyente, del 22 de setiembre de 1983 (pág 64 sgts), se evidencia de manera clara los aportes del Diputado González Camacho, hablando del carácter supranacional del Comité Ejecutivo y del Consejo, y también se refirió al Proyecto del Tratado de la Comunidad Económica y Social Centroamericana indicando que éste '... sigue muy de cerca la política y los lineamientos del Tratado de la Comunidad Económica Europea...'. Por ello sugirió en su intervención la incorporación de la frase relativa a la creación de organismos con funciones supranacionales, para hacer funcionar verdaderamente el proceso de integración Centroamericana." (...) "La Carta Magna de Guatemala, del 31 de mayo de 1985 y sus reformas, reconoce expresamente la Comunidad Centroamericana en el artículo 150, estableciéndose el deber de adoptar las medidas adecuadas para llevar a la práctica la unión política o económica de la antigua Federación Centroamericana. Para tal fin, el Congreso debe aprobar, previamente a su ratificación, los Tratados que 'atribuyan o transfieran competencias a organismos, creados dentro de un ordenamiento jurídico-comunitario concentrado para realizar objetivos regionales y comunes' (art. 171, I, 2)." (...) En los otros países hay disposiciones más o menos explícitas, o bien implícitas, a favor de la integración, sin hacer referencia expresa a la atribución de competencias supranacionales. La Constitución de Nicaragua, del 19 de noviembre de 1986 y sus reformas al establecer en el Título I los principios fundamentales 'privilegia la integración regional y propugna por la reconstrucción de la Gran Patria Centroamericana', disponiendo además que el pueblo de Nicaragua es 'parte integrante de la nación centroamericana' (art. 5 in fine y 8). En el reconocimiento y defensa de la unidad centroamericana, apoya y promueve los esfuerzos encaminados a la integración política y económica y, además, "participará con los demás países centroamericanos y latinoamericanos en la creación o elección de organismos necesarios para tales fines (art. 9)." (...) "La Constitución Política de Honduras (Decreto n. 131, del 11 de enero de 1982) se refiere en su Preámbulo a 'la fe puesta en la restauración de la unión centroamericana'. No contiene normas expresas sobre la creación de Órganos comunitarios. Sin embargo, al referirse a las relaciones económicas con otros países, reconoce el proceso de integración económica centroamericana y el respeto a los tratados y convenios que suscriba (art. 335), los cuales una vez aprobados por el Congreso y ratificados por el Ejecutivo entran a formar parte del derecho interno y prevalecen sobre la legislación interna (artículos 16 y 18)." (...) "En Panamá, la Constitución Política, del 11 de octubre de 1972 y sus reformas, hace referencia únicamente en su Preámbulo a la promoción de la integración regional como fin del Estado. Las disposiciones relativas a los Tratados internacionales no establecen nada específico sobre la creación de órganos supranacionales, y por ende existen verdaderas limitaciones constitucionales para que este país pueda avanzar en el proceso." (...) ". La Constitución Política de Belice, adoptada el 21 de setiembre de 1982, establece en su artículo 1, inciso 1, que Belice aspira a conformar un Estado soberano y democrático de América Central en la región del Caribe, con lo cual existe una proclamación expresa de su interés por formar parte de la Comunidad Centroamericana. Posteriormente, en el inciso 2), incorpora el principio de supremacía constitucional." (...) "En la Constitución adoptada el 26 de enero del 2010, República Dominicana ingresa al proceso de constitucionalización del Derecho Internacional y, en tal reforma, incorpora normas relativas al proceso de integración. Si bien en su artículo 6 afirma el principio de supremacía constitucional, en el artículo 26 contiene una serie de disposiciones a favor de los procesos de integración regional, al respecto, es importante
} citar los incisos 4, 5 y 6 de dicha norma constitucional." 


\section{Democracia}

Dentro da Comunidade Andina de Nações, a situação não é diferente. Muito embora a jurisprudência do Tribunal de Justiça da Comunidade Andina reconheça a existência de um Direito Comunitário em seus Acórdãos proferidos nos pedidos de Interpretação Prejudicial, ${ }^{26}$ constata-se que o número de pronunciamentos do Tribunal Andino, nos últimos anos, não foi muito grande, conforme mostra o Gráfico $1 .{ }^{27}$

Gráfico 1 - Número de pronunciamentos do Tribunal Andino nos últimos anos

\begin{tabular}{|l|r|}
\hline \multicolumn{1}{|c|}{ Años } & $\begin{array}{c}\text { Número de } \\
\text { Procesos }\end{array}$ \\
\hline 1985 & 0 \\
\hline 1986 & 0 \\
\hline 1987 & 1 \\
\hline 1988 & 4 \\
\hline 1989 & 7 \\
\hline 1990 & 6 \\
\hline 1991 & 4 \\
\hline 1992 & 3 \\
\hline 1993 & 6 \\
\hline 1994 & 10 \\
\hline 1995 & 34 \\
\hline 1996 & 32 \\
\hline 1997 & 32 \\
\hline 1998 & 45 \\
\hline 1999 & 41 \\
\hline 2000 & 77 \\
\hline 2001 & 70 \\
\hline 2002 & 100 \\
\hline 2003 & 134 \\
\hline 2004 & 171 \\
\hline 2005 & 233 \\
\hline 2006 & 198 \\
\hline 2007 & 199 \\
\hline 2008 & 131 \\
\hline 2009 & 149 \\
\hline 2010 & 126 \\
\hline 2011 & 190 \\
\hline 2012 & 176 \\
\hline TOTAL & 2179 \\
\hline & \\
\hline
\end{tabular}

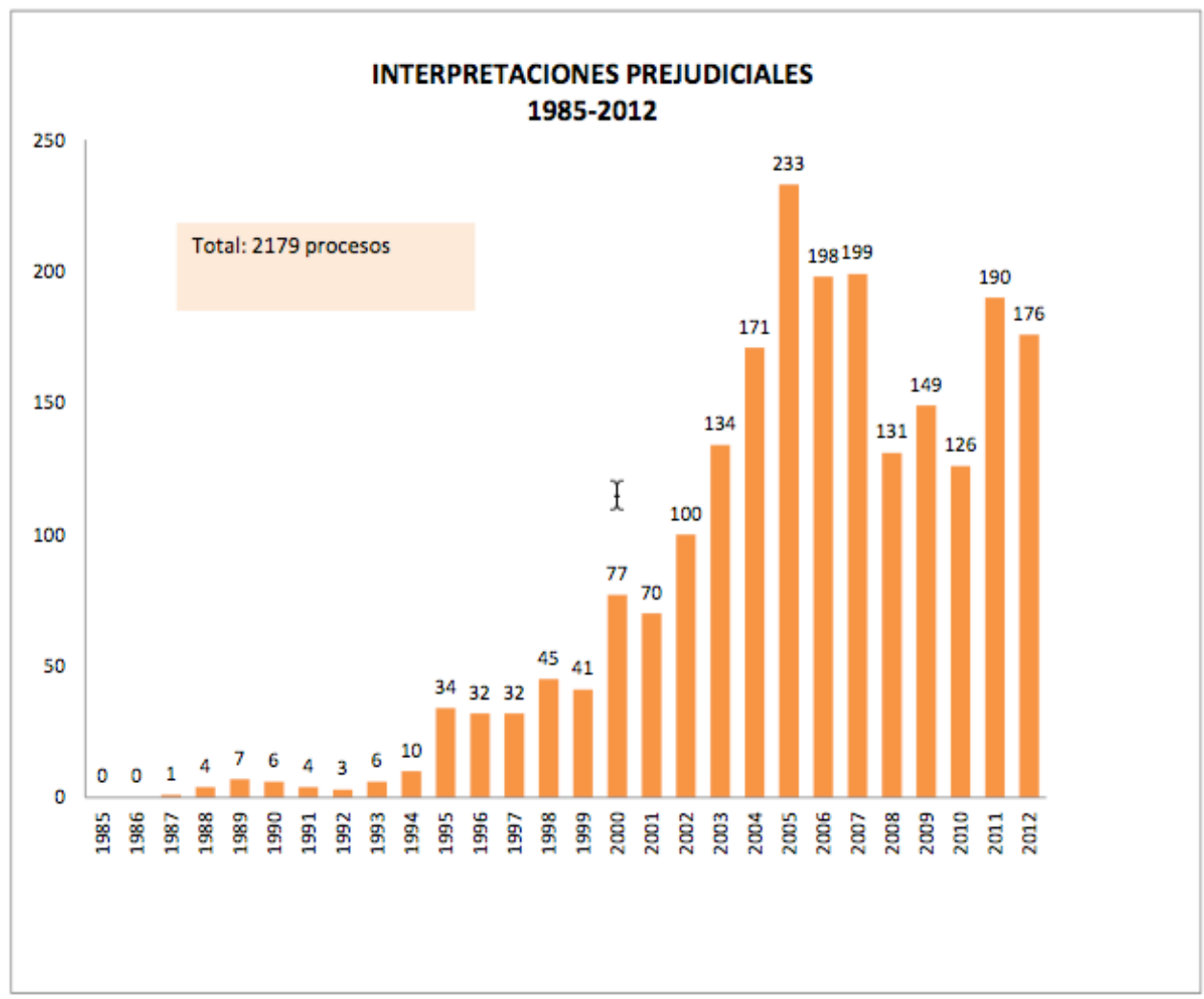

A existência, no ano de 2012, de um total de 176 Ações de Interpretação Prejudicial, bem demonstra a ineficácia do sistema do Direito Comunitário dentro da Comunidade Andina de Nações, posto que, no período de 1985 até 2012, foram julgados somente um total de 2.179 casos de Interpretação Prejudicial, o que, por si só, já comprova a tese desenvolvida

\footnotetext{
${ }^{26}$ Disponível em: http://server.tribunalandino.org.ec/sitetjca/index.php?option=com_wrapper\&view=wrapper\&ltemid=34. Acesso em: 5 mar. 2014.

27 Disponível em: http://server.tribunalandino.org.ec/sitetjca/index.php?option=com_wrapper\&view=wrapper\&ltemid=24. Acesso em: 5 mar. 2014.
} 
no presente artigo. ${ }^{28}$ De um lado, nos ordenamentos constitucionais dos Estados-partes da Comunidade Andina de Nações, contrariamente dos Estados que integram o Sistema Centro-Americano de Integração, inexistem dispositivos expressos, de forma a admitir a existência do Direito Comunitário; por outro, os respectivos ordenamentos constitucionais adotam a primazia das normas constitucionais.

Assim, muito embora reconheça-se a existência de um "Direito Comunitário derivado" nos respectivos processos de integração, a sua eficácia é totalmente questionável, e, diferentemente do verdadeiro "Direito Comunitário europeu", no qual, em razão da sua própria

\footnotetext{
${ }^{28}$ Vale destacar os dispositivos constitucionais dos Estados-partes da CAN, a saber: Bolívia (adotada em 24.11.2007): Artículo 256. I. Los tratados internacionales ratificados forman parte del ordenamiento jurídico interno con rango de ley.

II. Requerirán de aprobación mediante referendo popular vinculante previo a la ratificación los tratados internacionales que impliquen: (...)

2. Integración monetaria.

3. Integración económica estructural.

4. Cesión de competencias institucionales a organismos internacionales o supranacionales, en el marco de procesos de integración.

Constituição da Colômbia, adotada no ano de 1991:
}

Articulo 227. El Estado promoverá la integración económica, social y política con las demás naciones y especialmente, con los países de América Latina y del Caribe mediante la celebración de tratados que sobre bases de equidad, igualdad y reciprocidad, creen organismos supranacionales, inclusive para conformar una comunidad latinoamericana de naciones. La ley podrá establecer elecciones directas para la constitución del Parlamento Andino y del Parlamento Latinoamericano. Constituição do Equador, adotada no ano de 2008:

Art. 423. La integración, en especial con los países de Latinoamérica y el Caribe será un objetivo estratégico del Estado. En todas las instancias y procesos de integración, el Estado ecuatoriano se comprometerá a:

1. Impulsar la integración económica, equitativa, solidaria y complementaria; la unidad productiva, financiera y monetaria; la adopción de una política económica internacional común; el fomento de políticas de compensación para superar las asimetrías regionales; y el comercio regional, con énfasis en bienes de alto valor agregado.

2. Promover estrategias conjuntas de manejo sustentable del patrimonio natural, en especial la regulación de la actividad extractiva; la cooperación y complementación energética sustentable; la conservación de la biodiversidad, los ecosistemas y el agua; la investigación, el desarrollo científico y el intercambio de conocimiento y tecnología; y la implementación de estrategias coordinadas de soberanía alimentaria.

3. Fortalecer la armonización de las legislaciones nacionales con énfasis en los derechos y regímenes laboral, migratorio, fronterizo, ambiental, social, educativo, cultural y de salud pública, de acuerdo con los principios de progresividad y de no regresividad.

Constituição do Peru, adotada no ano de 1993:

Artículo $55^{\circ}$. Los tratados celebrados por el Estado y en vigor forman parte del derecho nacional.

Artículo $56^{\circ}$. Los tratados deben ser aprobados por el Congreso antes de su ratificación por el Presidente de la República, siempre que versen sobre las siguientes materias: (...)

2. Soberanía, dominio o integridad del Estado.

Cuando el tratado afecte disposiciones constitucionales debe ser aprobado por el mismo procedimiento que rige la reforma de la Constitución, antes de ser ratificado por el Presidente de la República.

La denuncia de los tratados es potestad del Presidente de la República, con cargo de dar cuenta al Congreso. En el caso de los tratados sujetos a aprobación del Congreso, la denuncia requiere aprobación previa de éste. (...)

4. Proteger y promover la diversidad cultural, el ejercicio de la interculturalidad, la conservación del patrimonio cultural y la memoria común de América Latina y del Caribe, así como la creación de redes de comunicación y de un mercado común para las industrias culturales.

5. Propiciar la creación de la ciudadanía latinoamericana y caribeña; la libre circulación de las personas en la región; la implementación de políticas que garanticen los derechos humanos de las poblaciones de frontera y de los refugiados; y la protección común de los latinoamericanos y caribeños en los países de tránsito y destino migratorio.

6. Impulsar una política común de defensa que consolide una alianza estratégica para fortalecer la soberanía de los países y de la región.

7. Favorecer la consolidación de organizaciones de carácter supranacional conformadas por Estados de América Latina y del Caribe, así como la suscripción de tratados y otros instrumentos internacionales de integración regional. 


\section{Humanos e \\ Democracia}

eficácia e autonomia, não é necessário o chamado controle de convencionalidade (em virtude da aplicação e observância de suas normas), nos casos da CAN e do Sica o cumprimento das normativas supranacionais depende de ações positivas dos respectivos Estados.

Por se tratar, conforme mencionado no presente artigo, de um Direito Comunitário híbrido ou imperfeito, uma vez que as Constituições dos Estados não contemplam dispositivos constitucionais de forma a contemplar a supranacionalidade (como nos casos dos Estados que integram a CAN), quer pela ausência da vontade política dos Estados e pela falta de verdadeiras instituições supranacionais (como nos casos de ambos os blocos econômicos), sempre haverá a supremacia da constituição ante os tratados.

Assim, como forma de se buscar compatibilizar as normas emanadas pelas instituições de ambos os blocos econômicos, dentro dos ordenamentos jurídicos nacionais dos Estados, de forma a garantir a efetividade no cumprimento das respectivas normas, torna-se necessário a retomada do processo de controle de convencionalidade adotado dentro do Direito Internacional Público, de forma a garantir o primado do chamado "Direito Comunitário" perante os ordenamentos jurídicos dos Estados.

O referido controle de convencionalidade, nas palavras de Valério Mazzuoli, tem por objetivo assegurar, no campo dos Direitos Humanos, a primazia da norma internacional diante dos ordenamentos jurídicos dos Estados e a sua compatibilidade, sob pena de ensejar a responsabilidade internacional do Estado.

Nos casos da Comunidade Andina de Nações e do Sistema Centro-Americano de Integração, a questão torna-se muito nebulosa e caminha-se por temas e conceitos controversos, pois, ainda que se admita a existência de um ordenamento jurídico comunitário dentro desses blocos econômicos, parece-nos que o seu direito derivado não é efetivo.

Assim, resta uma pergunta a ser respondida: Se os instrumentos construídos a partir do Direito Comunitário europeu comprovaram que não podem ser aplicados dentro da CAN e do Sica, como garantir a efetividade na aplicação do respectivo Direito Comunitário híbrido? Concretamente, tendo em vista as realidades constitucionais dos respectivos Estados, a ausência de instituições verdadeiramente supranacionais e o fato de os países adotarem o conceito clássico de soberania, a resposta não deve ser outra, a não ser a necessidade de as Cortes Constitucionais garantirem a aplicação das normas em seus ordenamentos jurídicos internos.

Ou seja: ainda que as Cortes supranacionais de ambos os blocos econômicos reconheçam a existência e a obrigatoriedade do Direito Comunitário, o seu cumprimento dependerá da vontade política dos respectivos Estados.

Levando-se em consideração que, mesmo dentro dos blocos econômicos supranacionais, ora analisados, os objetivos integracionistas são voltados para atender aos interesses da pessoa humana e, consequentemente, os direitos fundamentais de seus jurisdicionados, e dentro do modelo jurídico construído pelos Estados, tanto na CAN quanto no Sica, é necessário render-se à realidade quanto à existência de um modelo supranacional híbrido e reconhecer que, dentro do sistema proposto, diferentemente da União Europeia, para garantir a efetividade na aplicação das normas dos blocos torna-se necessário admitir o controle de convencionalidade. 


\section{CONSIDERAÇÕES FINAIS}

Incontestável é a realidade inexorável da formação dos blocos econômicos e a necessidade de os Estados adotarem políticas voltadas à concretização dos objetivos comuns estabelecidos dentro dos tratados institucionais. Para tanto, cria-se um direito derivado com a adoção de normas comuns, com vistas à concretização das políticas a serem efetivadas dentro da integração.

Nas políticas integracionistas torna-se mais comum a adoção das questões voltadas ao principal sujeito da integração, que é a pessoa humana. A grande dificuldade, todavia, encontrada em qualquer processo de integração, diz respeito ao cumprimento de tais normativas (representadas pelo direito derivado).

No caso da União Europeia, criou-se um direito peculiar a partir do Direito Internacional Público, que é, ao mesmo tempo, independente e autônomo ante o direito interno e diante do direito internacional, de forma a garantir a maior eficácia no cumprimento das decisões, o chamado Direito Comunitário ou Direito da União Europeia.

O grande sucesso do Direito supranacional da União Europeia reside no próprio histórico da construção daquele bloco econômico, assim como na existência de umas verdadeiras instituições supranacionais e na abertura constitucional, existente nos ordenamentos jurídicos dos Estados-membros, que admitem a transferência de soberania às instituições supranacionais.

Esta, entretanto, não é a realidade encontrada dentro da Comunidade Andina de Nações e no Sistema Centro-Americano de Integração, pois, a despeito de ambos os blocos econômicos aplicarem o Direito Comunitário, como visto anteriormente, a efetividade no cumprimento do chamado direito derivado é duvidosa.

Por isso, procurou-se denominar o ordenamento jurídico adotado em ambos os blocos econômicos como um Direito Comunitário híbrido, tendo em vista as grandes diferenças entre a realidade existente na União Europeia ante a CAN e o Sica. No caso dos dois últimos blocos econômicos, em que a efetividade no cumprimento das normativas é duvidosa, torna-se importante utilizar-se da teoria do Direito Internacional Público, com o intuito de garantir a aplicação do direito derivado.

Assim, defende-se a ideia e a necessidade da utilização do conhecido controle de convencionalidade dentro dos respectivos processos de integração, como forma de garantir o constante diálogo entre a Corte Centro-Americana de Justiça e o Tribunal de Justiça Andino com as jurisdições nacionais dos Estados que integram os blocos econômicos, cabendo ao juiz nacional, de forma efetiva, aplicar o direito comunitário derivado.

\section{REFERÊNCIAS}

ARROYAVE-QUINTERO, M. A. Ineficacia crónica del derecho andino: uno de los factores importantes para el ocaso de la Comunidad Andina de Naciones (CAN). Papel Político, [on-line], 13, enero/jun. 2008. Disponível em: http://www.redalyc.org/articulo.oa?id=77716563009. Acesso em: 4 marzo 2014.

BALDI, César Augusto. Novo constitucionalismo latino-americano: considerações conceituais e epistemológicas. In: WOLKMER, Antonio Carlos; CORREAS, Oscar (org.). Crítica jurídica na América Latina. Aguas Calientes; Florianópolis: Centro de Estudios Jurídicos y Sociales Mispat; Universidade Federal de Santa Catarina, 2013.

CAMPOS, João Mota de. Direito comunitário. 4. ed. Lisboa: Calouste Gulbenkian, 1994. V. 2. 
FONTOURA, Jorge. Fontes e formas para uma disciplina jurídica comunitária. Informativo Mercosul, Comissão Parlamentar Conjunta do Mercosul. Seção Brasileira, v. 1, n. 3, p. 43, dez. 1996/jan. 1997.

FONTOURA, Jorge. A construção jurisprudencial do direito comunitário europeu. In: PIMENTEL, Luiz Otávio (org.). Mercosul no cenário internacional. Direito e sociedade. Curitiba: Juruá, 1998. p. 293.

GOMES, E. B. Democracia e direitos fundamentais na União Européia: a questão do multiculturalismo. Curitiba: Juruá, 2011.

GRANDE, C. E. S.; CHACÓN, E. N. U. Manual de Derecho Comunitário Centroamericano. 2. ed. El Salvador: El Dorado de Talleres Impresiones, 2013.

HABERMAS, J. A constelação pós-nacional. Ensaios políticos. São Paulo: Littera Mundi, 2001.

HABERMAS, J. A inclusão do outro. São Paulo: Loyola, 2002.

LLORENTE, F. R.; PÉREZ, M. D. Constituciones de la Unión Europea. Barcelona: Ariel, 1997.

TEIXEIRA, Antonio Fernando Dias. A natureza jurídica das Comunidades Européias. Coimbra: Almedina, 1993.

WINTER, L. A. C.; WASCHOWSKI, M. Estado: construção de uma identidade. CONPEDI DE MANAUS. Anais [...]. Disponível em: http://www.conpedi.org.br/manaus/arquivos/anais/bh/luis_alexandre_carta_winter.pdf. Acesso em: 5 mar. 2014. 